\title{
Guidelines versus practice: UK asthma nurses often recommend intermittent, symptom-driven use of inhaled corticosteroids
}

\section{*Michael E Hylanda, Sue Blake ${ }^{b}$, Colin J Greavesc, Margaret Pinnuck ${ }^{\mathrm{b}}$, Clare Seamark $^{\mathrm{b}}$, Dave Seamark, ${ }^{\mathrm{b}}$ David Ward ${ }^{\mathrm{b}}$, David MG Halpin ${ }^{\mathrm{d}}$}

a School of Psychology, University of Plymouth, Plymouth, Devon, UK

${ }^{b}$ Honiton Group Practice, Marlpits Lane, Honiton, Devon, UK

' Peninsula Medical School (Primary Care), Postgraduate Medical Centre, Barrack Road, Exeter, Devon, UK

${ }^{\mathrm{d}}$ Department of Respiratory Medicine, Royal Devon and Exeter Hospital, Devon, UK

Received 19th July 2007; revised version received 13th March 2008; accepted 14th September 2008; online 15th October 2008

\begin{abstract}
Background: Recent clinical trials suggest that intermittent use of inhaled corticosteroids (ICS) is safe for mild persistent asthma. Intermittent ICS use is inconsistent with current guidelines but is a common form of non-compliance. The aim of this study was to investigate how asthma nurses advise patients to use ICS.

Methods: Practice managers of 241 GP surgeries in the southwest of England were sent questionnaires to distribute to practice nurses. Results: Questionnaires were returned by 105 nurses (104 had asthma-specific training). There was a wide variation in attitudes to guideline-based care and advice given to patients. $97 \%$ indicated that they sometimes advised patients to decrease their ICS use, $85 \%$ sometimes advised patients to stop their ICS when their asthma was well controlled, and $70 \%$ reported sometimes advising intermittent use.

Conclusion: Asthma nurse recommendations are often inconsistent with guidelines. There is considerable variation between different asthma nurses in the advice given to patients.

(C) 2009 General Practice Airways Group. All rights reserved.

ME Hyland et al. Prim Care Resp J 2009; 18(2): 114-117.

doi:10.3132/pcrj.2008.00066
\end{abstract}

Keywords Guidelines, compliance, nurse management, adherence, concordance, asthma

\section{Introduction}

International' ${ }^{1}$ and national ${ }^{2}$ asthma treatment guidelines recommend regular use of inhaled corticosteroids (ICS) for mild persistent asthma. ICS dose may be increased during exacerbations, but decreases in dosage are exceptional and require careful monitoring by health professionals. In contrast to guideline recommendations, clinical trials have shown symptomatic use of ICS to be safe in mild asthma., ${ }^{3,4} \mathrm{~A}$ review of population studies shows non-compliance to be unrelated to symptoms, ${ }^{5}$ and symptom-driven (or symptom-responsive) use of ICS is common and not associated with worse outcomes in mild asthma. ${ }^{6}$

The majority of primary care asthma management in the
UK is provided by asthma nurses who, it is often assumed, operate according to national or international guidelines as directed by their employer, the primary care physician. The aim of this study was to ascertain - notwithstanding guideline recommendations - whether or not asthma nurses sometimes recommend or approve treatment with intermittent symptom-driven use of ICS.

\section{Methods}

Letters were sent to the practice managers of all 241 general practices in Devon and Cornwall, England - as identified through the Local Primary Care Research Network database enclosing two identical questionnaires with a request that

* Corresponding author: Dr Michael E Hyland, School of Psychology, University of Plymouth, Plymouth, Devon, UK.

Tel: +44 (0)1752 233144 Fax: +44 (0)1752 584800 E-mail: mhyland@plymouth.ac.uk 
these questionnaires should be filled in anonymously by the asthma nurse or nurses and returned in a reply paid envelope. The questionnaire (see Tables 1 and 2) was specifically designed for this study and was piloted by six practice nurses whose feedback was incorporated into the final version. The questionnaires were numbered by practice, and if no return was received, one reminder letter was sent to the practice manager. Approval was given by the local ethics committee, but further contact with nurses or practice managers was prohibited by the ethics committee.

In addition to demographic questions, the questionnaire asked the nurses seven questions about their patient management behaviour, including three questions about intermittent ICS use. In addition, there were six attitudinal questions to help explain the reasons for the nurses' behaviour. We calculated Spearman correlations to compare responses to behavioural and attitudinal statements.

\section{Results}

Seven practices declined to participate and letters to three were returned unopened due to an out-of-date address. Completed questionnaires were received from 93 practices providing data from 105 asthma nurses (104 female, 1 male) of whom two were age 20-29, 16 (15\%) were age 30-39, 50 (48\%) were age 40-49, and 37 (35\%) were older than 49 years. The length of time working as an asthma nurse varied between 1-20 years, mean 8.5 years, SD 4.8. All but one reported receiving asthma-specific training, though the type of training was not specified. One reported following no guidelines, two followed only local guidelines, 59 only national guidelines, 42 national and international guidelines, and one followed national, international and local guidelines.

Responses to the behavioural questions are shown in Table 1. Of the total sample of nurses, 97\% indicated that they sometimes advised patients to decrease their ICS use and $29 \%$ gave this advice to all patients, $85 \%$ sometimes advised patients to stop their ICS when their asthma was well controlled and $16 \%$ gave this advice to all patients, $70 \%$ reported sometimes advising intermittent use, and $5 \%$ always gave this advice. Table 2 shows responses to the attitudinal questions. Most nurses agreed to some degree with the statement that it was important to adhere to guidelines when advising patients (Table 2), but there was a range of opinions on whether nurses knew better than patients; most agreed that it was important to individualise advice, taking into account patients' views on ICS.

The three questions about ICS advice (decreasing, stopping, and intermittent use, i.e., questions 2, 3 and 4 - see Table 1) were correlated with each of the attitudinal statements in order to investigate why nurses gave the advice they gave. None of these three behavioural questions correlated with attitudes to guidelines (i.e., questions 2, 4, and 5 - see Table 2). However, nurses who believed that the "nurse knows much more" than the patient (question 2, Table 2) were less likely to recommend an increase in ICS when symptoms worsen (rho $=-.25, \mathrm{p}<0.05$ ), a decrease when asthma is well controlled (rho $=-.24, p<0.01$ ), or cessation when asthma is well controlled (rho $=.-27, \mathrm{p}<$ 0.05 ). Nurses who believed they should not intervene when the patient's strategy was working (question 4, Table 2) were more likely to recommend cessation of ICS when asthma is well controlled (rho $=.43, \mathrm{p}<0.01)$.

\section{Discussion}

We found that almost all asthma nurses in our sample sometimes recommend a reduction in ICS when asthma is well controlled, and $85 \%$ sometimes recommend stopping ICS under these circumstances. These recommendations are given by most nurses only for some patients. Our data suggest that many nurses individualise the advice given to patients, since the majority do not give the same advice to all patients, including the advice to increase dosage during exacerbations. However, we found considerable variation in the way nurses manage their patients with regards to ICS use, in that the proportion of patients being given a particular type of advice varies between nurses. Variation in advice was unrelated to using international versus national guidelines. By contrast, we found considerable consistency in the way nurses checked on inhaler use, with the majority checking up on all patients (questions 4, 5, 6 - see Table 1).

We included attitudinal questions to attempt to explain why nurses managed patients in the way they did. In general, nurses agreed that it was important to adhere to guidelines, but the majority also agreed that it was important to balance advice in guidelines with patients' views on ICS. Nurses varied in giving advice about symptom-driven intermittent use of ICS, but this variation was unrelated to their attitude towards guidelines. Nurses therefore recommend intermittent ICS not because they disagree with guideline recommendations, but because they trust the patient's understanding of asthma and do not believe that the nurse 'always knows best'.

In conclusion, clinical trial and population data show that symptomatic use of ICS is safe for mild asthma. ${ }^{3-5}$ In our study, we found that most asthma nurses sometimes recommend intermittent symptom-driven use of ICS to selected patients. However, there is considerable variation in practice between respiratory nurses. Irrespective of whether asthma guidelines are correct, it seems clear that guidelines are not achieving one of their main objectives - i.e. achieving greater consistency in patient management. For that reason alone, international and national guidelines need revision. 
ME Hyland et al.

Table 1. Number of respiratory nurses engaging in different kinds of management behaviour $(n=105)$.

$\begin{array}{llllllllll}\text { None } & 10 \% & 20 \% & 30 \% & 40 \% & 50 \% & 60 \% & 70 \% & 80 \% & 90 \%\end{array}$

1. What percentage of patients do you advise should temporarily

increase the dose of inhaled if their symptoms worsen or peak flow falls?

$\begin{array}{lllllllllll}4 & 4 & 5 & 4 & 2 & 9 & 6 & 8 & 7 & 14 & 39\end{array}$

2. How often do you advise patients that they can temporarily decrease the dose of inhaled corticosteroids if they are well controlled?

$\begin{array}{lllllllllll}3 & 7 & 4 & 11 & 9 & 7 & 10 & 8 & 4 & 11 & 30\end{array}$

3. How often do you advise patients at BTS Step $2 *$ that they can temporarily stop their inhaled corticosteroids if they are well controlled?

$\begin{array}{lllllllllll}16 & 16 & 5 & 10 & 6 & 12 & 4 & 9 & 1 & 7 & 17\end{array}$

4. How often do you advise patients at BTS Step 2* that they can take inhaled corticosteroids intermittently, e.g., take them only if they have a cold?

$\begin{array}{lllllllllll}32 & 4 & 18 & 10 & 3 & 6 & 3 & 7 & 11 & 1 & 5\end{array}$

5. When reviewing patients do you ask if they are using less inhaled steroid than prescribed?

6. Do you ask patients about their strategy for ICS use, e.g., how they decide when to use their medication?

7. When reviewing patients do you check if their requests for repeat prescriptions broadly correlates with the number they would need if taking the prescribed dose?

$\begin{array}{llllllllllll}1 & 1 & 3 & 3 & 1 & 2 & 2 & 3 & 7 & 7 & 74\end{array}$

*Regular inhaled steroids, standard dose, only.

Table 2. Number of respiratory nurses agreeing or disagreeing with attitudinal statements $(n=105)$.

\begin{tabular}{|c|c|c|c|c|c|c|c|}
\hline & $\begin{array}{l}\text { Strongly } \\
\text { disagree }\end{array}$ & Disagree & $\begin{array}{l}\text { Slightly } \\
\text { disagree }\end{array}$ & Neutral & $\begin{array}{l}\text { Slightly } \\
\text { agree }\end{array}$ & Agree & $\begin{array}{l}\text { Strongly } \\
\text { agree }\end{array}$ \\
\hline \multicolumn{8}{|l|}{$\begin{array}{l}\text { 1. I feel it is important to always adhere to the } \\
\text { guidelines when advising patients on their use of }\end{array}$} \\
\hline ICS medication. & 0 & 1 & 12 & 15 & 24 & 40 & 13 \\
\hline \multicolumn{8}{|l|}{$\begin{array}{l}\text { 2. In general the Asthma Nurse knows much more } \\
\text { about the best way to treat asthma compared with }\end{array}$} \\
\hline the patient. & 0 & 19 & 20 & 18 & 24 & 22 & 2 \\
\hline \multicolumn{8}{|l|}{$\begin{array}{l}\text { 3. Where a patient has an ICS medication strategy } \\
\text { that seems to work for them, (e.g. ceasing ICS } \\
\text { medication when asthma seems controlled) I am }\end{array}$} \\
\hline happy for them to continue. & 0 & 3 & 7 & 6 & 22 & 62 & 4 \\
\hline \multicolumn{8}{|l|}{ 4. I often find myself giving advice regarding ICS } \\
\hline medication use which does not follow the guidelines. & 8 & 37 & 19 & 18 & 19 & 3 & 0 \\
\hline \multicolumn{8}{|l|}{ 5. It is important to balance the patient's views on } \\
\hline ICS usage with the advice given in the guidelines. & 0 & 3 & 5 & 9 & 27 & 51 & 9 \\
\hline \multicolumn{8}{|l|}{$\begin{array}{l}\text { 6. Individual patients have insight into their own } \\
\text { asthma which in certain circumstances allows them }\end{array}$} \\
\hline to ignore the advice of the practice asthma nurse. & 0 & 3 & 19 & 30 & 28 & 25 & 0 \\
\hline
\end{tabular}




\section{Conflict of interest declaration}

All authors are members of the East Devon Respiratory Research Group whose annual dinner is funded by GlaxoSmithKline (GSK). DH has received sponsorship to attend international meetings, and honoraria for lecturing, attending advisory boards and preparing educational materials, from Altana, AstraZeneca, GSK, Pfizer and Boehringer Ingelheim.

\section{References}

1. Global Initiative for Asthma. Global strategy for asthma management and prevention: NHLBI/WHO workshop report. Bethesda, MD: National Heart, Lung, and Blood Institute, 2006. (http://www.ginasthma.org.)

2. British Thoracic Society, Scottish Intercollegiate Guidelines Network (SIGN). British guideline on the management of asthma. Thorax 2003;58(Suppl I):i1-94.
3. Papi A, Canonica GW, Maestrelli P et al. Rescue Use of Beclomethasone and Albuterol in a Single Inhaler for Mild Asthma. N Engl J Med 2007;356:204052. http://dx.doi.org/10.1056/NEJMoa063861

4. Boushey HA, Sorkness CA, King TS et al. Daily versus as-needed corticosteroids for mild persistent asthma. N Engl J Med 2005;352:1419-28. http://dx.doi.org/10.1056/NEJMoa042552

5. Osman LM, Hyland ME. Adherence and self management. In: Peter Gibson, Michael Abramson, Ulrich Costabel, Michael Hensley, Jimmy Volmink, Richard Wood-Baker (Editors) Evidence based respiratory medicine, 2005. pp 91-105. London, BMJ Books.

6. Greaves CJ, Hyland ME, Halpin DMG, Blake S, Seamark D. Patterns of corticosteroid medication use: Non-adherence can be effective in milder asthma. Prim Care Resp J 2005;14:99-105. http://dx.doi.org/ 10.1016/j.pcrj.2004.09.005 